\title{
Ciudad de la memoria de José Emilio Pacheco: hacia la creación de un único poemario
}

\author{
María Rosa Olivera-Willams \\ University of Notre Dame
}

"Poema: cópula de la imagen virtual con la palabra potencial. Poetizar: Teatro de la lengua, retablo del mundo: simulacro. En poesía, la lectura es siempre múltiple."

Saúl Yurkievich.

"La poesía no es de nadie: se hace entre todos."

Lautréamont/Julián Hemández/José Emilio Pacheco.

Desde 1963, fecha de la publicación de Los elementos de la noche, la labor poética de José Emilio Pacheco se ha constituido en una actividad constante y rigurosa. En el presente, a los cincuenta años de edad, Pacheco es el autor de nueve libros de poemas, y no existe antología de la reciente poesía mexicana e hispanoamericana que no lo incluya. El unánime espaldarazo de la crítica - la ya lejana polémica de 1976-78 entre el crítico Rodríguez-Alcalá y el poeta Gabriel Zaid merece olvido- y la gran popularidad de la obra de Pacheco, especialmente de su poesía, le ganaron en 1986 la elección a El Colegio Nacional.

La crítica reconoce que a partir de No me preguntes cómo pasa el tiempo (1969), libro ganador del "Premio Nacional de Poesía" en el Segundo Certamen Nacional de Aguascalientes, Pacheco descubre su propia voz. Una voz que es irónica e irreverente 
(Oviedo); una voz que es más bien "llana" y que trata de acercarse a los registros del habla conversacional (Doudoroff). Si bien es cierto que No me preguntes... inicia la madurez del poeta mexicano, también es cierto que este segundo ciclo de la obra de Pacheco no introduce necesariamente un corte con sus libros anteriores, sino una progresión. Conviene tener presente que para Pacheco el poeta existe siempre en un estado de transicion. Releyendo y reescri- biendo un poema de Roberto Femández Retamar, dice así en su "Manifiesto", de Irás y no volverás:

\section{Todos somos poetas de transición \\ La poesía jamás se queda inmóvil (107).}

Cuando los críticos clasifican la poesía de Pacheco como "conversacional", parecen decir que se trata de una lírica de lo cotidiano, de lo claro, lo sentimental, lo irónico y sobre todo lo social. Es un concepto amplio, que abarca temas desarrollados por otras tendencias poéticas. El tono coloquial, una de las características esenciales de la poesía conversacional, íntimamente relacionada con el lenguaje, tiene sus raíces en William Wordsworth. En el prologo a sus Lyrical Ballads (1802), Wordsworth proponía para sus poemas un lenguaje que se acercara al lenguaje real de los hombres sencillos. El lenguaje de su nueva poesía se separaba de lo que hasta el momento se entendía por dicción poética e incorporaba palabras, frases y figuras verbales usadas en la conversación o en la prosa. Su búsqueda de un lenguaje poético carente de artificios y sofisticación muestra el deseo de encontrar un medio lingüístico que le permitiera aprehender la verdad. Para Wordsworth "el lenguaje de una buena parte de cada poema, aun de los de tono más elevado, no debe diferir en nada, salvo en el metro, del lenguaje de la buena prosa". Son precisamente estas posiciones de la teoría poética de Wordsworth las que objeta Coleridge, coautor de las Lyrical Ballads (Coleridge 1986). Coleridge, quien subtitula el poema "The Nightingale", de Lyrical Ballads, 
"A Conversational Poem", crea un nuevo tipo de poesía. Si bien emplea un lenguaje sencillo, según la tendencia querida por Wordsworth, su novedad radica en la persona dramática. Lo conversacional de esta poesía se halla en el artificio de crear una "conversación" - de hecho, un monólogo- de la persona dramática con los miembros de la familia del poeta, lo que le permite al poeta hablar consigo mismo y de esta manera proyectar en sus poemas su forma de ser y de sentir.

El desarrollo de la persona poética es, a mi juicio, el elemento de mayor interés para entender la evolución de la poesía contemporánea. Por ello no se puede olvidar la importancia del "monólogo dramático" de Robert Browning, recurso que comenzó siendo una desviación de la norma poética y que "ahora se convertía en norma, de una manera u otra" (Jarrell). El monólogo dramático de Browning permite al poeta distanciarse del poema. La poesía contemporánea hispanoamericana, y especialmente la de José Emilio Pacheco, se enriquece si, en lugar de encerrarla dentro del vago término de "poesía conversacional", se estudia el desarrollo y las nuevas posibilidades del monólogo dramático.

La poesía de Pacheco es una poesía de los otros. Hablantes de otros textos y de otros tiempos se escuchan a través de las personas poéticas de Pacheco. El lenguaje a veces prosaico de sus poemas no marca el fin de la poesía, ni tampoco, como pensaba Wordsworth, indica que no hay diferencia entre el lenguaje poético y el de la prosa. El lenguaje prosaico de cierta poesía no puede ser leído como prosa, por el simple hecho de estar incorporado en el verso. Los espacios en blanco que separan los versos imponen nuevos significados a las palabras y frases (recuérdese el poema de William Carlos Williams, "This is just to say..."). Carlos Bousoño encuentra que el lenguaje familiar y prosaico, así como los recursos de distanciamiento utilizados para despersonalizar al hablante, son características de la "poesía poscontemporánea" (533-576). En la poesía de Pacheco la voz del poeta no se despersonaliza, desapareciendo del poema, sino que, en la tradición del monólogo dramático, se pierde entre las voces de los demás. 
Si bien Pacheco es un poeta de transición dentro de la historia de la poesía latinoamericana, cada uno de sus libros marca a su vez una transición en su propio derrotero poético. Esto explica las múltiples revisiones de sus primeros poemarios en Tarde o temprano, la antología que recoge su obra escrita entre 1963 y 1980. La poesía no puede permanecer estática, continuamente está rehaciéndose, reescribiéndose. Pero Pacheco no sólo retoma otros textos, otras voces, del pasado y del presente, otras lenguas - las "Aproximaciones" de Pacheco a poemas escritos en lenguas extranjeras o a traducciones de poemas a lenguas extranjeras-, sino también sus propios poemas. La recreación de textos propios parece responder a lo que Pedro Lastra llama "intertextualidad refleja" (Lastra; Soto 118). Pero en Pacheco no sólo un texto se fecunda a sí mismo, dando origen a otros, sino que poemas recientes promueven en él el deseo de revisar los anteriores; es lo que ocurre con Tarde o temprano. Un buen ejemplo de refundición de textos ajenos en un texto original y auténticamente pachequiano podría ser la serie de epigramas que titula "Juego de espejos (Catulo imita a Emesto Cardenal)" en Irás y no volverás (1973). El subtítulo, irónico y anacrónico, parece indicar que los epigramas de Cardenal, basados en la obra del poeta latino, llevan a Pacheco a reescribir los epigramas de Catulo, refundiendo así las voces de los poetas latino y nicaragüense en la suya propia.

No existe la obra cerrada, perfecta, pero en la obra de Pacheco sí existe una voluntad de perfección. Es esa voluntad de perfección la que le hace concebir cada nuevo libro de poemas como en una relación de continuidad con el que lo precede y de germen para con el que lo sucede. Así, en un esfuerzo que nos recuerda al de Gabriela Mistral, Al margen (1976) surge como un apéndice de Irás y no volverás (1973) y se incorpora en 1980 a Desde entonces. Jardín de niños (1978) también es integrado a Desde entonces; Prosa de la calavera (1981) pasa a ser una sección de Los trabajos del mar (1982), y doce poemas de Los trabajos del mar figuran, reescritos, en la edición ampliada del libro del mismo título, de 1983. 
Los críticos coinciden en la división de su obra en dos grandes periodos, el primero formado por Los elementos de la noche (1963) y El reposo del fuego (1966) y el segundo, por los restantes siete poemarios: No me preguntes cómo pasa el tiempo (1969), Irás y no volverás (1973), Islas a la deriva (1976), Desde entonces (1980), Los trabajos del mar (1983) y, ahora, Ciudad de la memoria (1989). Pero esos mismos críticos reconocen que, aun en su primera poesía, la menos anecdótica, la más difícil y hermética, en la que el artificio poético es trabajado con gran celo, ya se advierten claramente ciertos principios de la intertextualidad: la voz poética incorpora a otras voces, hay allí otros textos que se leen a través de los textos de Pacheco. Además, como bien nota Andrew Debicki, el hablante, que se presenta en un "estilo lírico", distanciándose de las imágenes que crea y de esta manera permitiéndole al lector compartir su experiencia vivida, en muchos poemas se separa del lector y de la realidad creada al incorporar la segunda persona del singular, el "tư", técnica que será ampliada y que en el resto de su obra despertará reacciones diversas en el lector. El poema 3 de la tercera sección de El reposo del fuego ilustra lo que acabamos de decir, y también muestra una constante preocupación por las circunstancias inmediatas:

La ciudad en estos años cambió tanto

que ya no es mi ciudad

su resonancia

de bóvedas en ecos

y los pasos

que ya no volvesán

Ecos pasos recuerdos destrucciones

Pasos que ya no son. Presencia tuya, hueca memoria resonando en vano.

Lugar que ya no está, donde pasaste, donde te vi por último, en la noche de ese ayer que me espera en los mañanas, de ese futuro que pasó a la historia, de este hoy continuo en que te estoy perdiendo (57). 
Los dos primeros libros, que parecen responder a la influencia surrealista y que naturalmente, a pesar de la maestría que Pacheco demuestra en el uso de la lengua, son producto de su periodo de aprendizaje, ya llevan en cierne todos los elementos que caracterizan la madurez del poeta. Su poesía debe, pues, estudiarse como un cuerpo orgánico que está en continuo crecimiento y autorrevisión. La obra de Pacheco se mueve hacia adelante, pero siempre retomando un impulso en lo ya creado. Siguiendo esta postura, estudiaremos su último libro de poemas, Ciudad de la memoria, como un nuevo capítulo de una obra única que insiste en permanecer abierta.

A diferencia de los anteriores, este poemario no se organiza en secciones. Treinta y cinco poemas que se entretejen libremente van desarrollando los temas constantes de Pacheco: el tiempo y sus derivados, la vejez, la muerte, el olvido y su envés, la memoria, la fugacidad de todo lo creado por el hombre, contrastada con la perennidad cíclica de la naturaleza, la imposibilidad de aprehender el presente, todo lo que aparece sintetizado en el epígrafe de Enrique Lihn con el cual se abre el libro: “...Vivimos todos en la ignorancia total, en la ciudad de la Memoria. Borrada"; así como las reflexiones sobre la poesía y el poeta; la violencia de este siglo que con pasos agigantados se acerca a su final; el bestiario alegórico con su crítica moral e irónica; y la infaltable presencia de otros poetas, ya que "la poesía se hace entre todos". Sin embargo, un tema parece sobresalir y reaparecer constantemente a través de los otros temas. Me refiero a la autorreflexión sobre la poesía.

El primer poema del libro, titulado "Caracol [Homenaje a Ramón López Velarde]", no está escrito en tercera persona ni en el tono impersonal que caracteriza a los bestiarios y fábulas de José Emilio Pacheco. El título nos lleva a pensar en otro poema suyo, "Fisiología de la babosa" (Irás y no volverás 28), y ello llevó a Pacheco a escribir una nota en la revista Vuelta, en 1977, explicando cómo los textos se atraen a pesar de quien los escribe - caso de intertextualidad involuntaria (Soto). Pero este poema, si se 
lee teniendo en cuenta a quién va dedicado, cambia el objetivo general de sus fábulas (los destinatarios de los juicios irónicos de Pacheco son los seres humanos en las sociedades del mundo occidental, especialmente la mexicana). En este caso el hablante, que se dirige al caracol usando la segunda persona del singular, le ofrece al lector una reflexión acerca del arte de crear. No es la primera vez que Pacheco se sirve de estas alegorías zoológicas para referirse a la poesía. En la sección "Los animales saben" de No me preguntes cómo pasa el tiempo, el poema titulado "Los grillos (defensa e ilustración de la poesía)", presenta el indescifrable sonido que producen los grillos al entrechocar sus élitros como una alegoría del problema del poder comunicativo de la escritura del poeta. Pero en este caso, al crear un distanciamiento entre lo que dice y su receptor, el hablante recrea el arte de escribir poesía como un arte de ocultamiento. No se trata de una poesía confesional:

\footnotetext{
Tú, como todos, eres lo que ocultas. Debajo del palacio tornasolado, flor calcárea del mar o ciudadela que en vano tratamos de fingir con nuestro arte, te escondes indefenso y abandonado, artifice o gusano: caracol (11).
}

La coraza, lá creación, la secreción del caracol, por la cual es caracol y no babosa, le permite a su creador un instante más de vida en la fugacidad de todo lo terreno. A través de su "concha", el caracol deja su "huella" en este reino de lo caduco. Pero - y aquí reside la ironía - su concha, ese "castillo de naipes" que se alza "ante el océano de las horas", el continente del eco del mar donde "circulan" "las palabras" del "idioma", digámoslo de una vez, el poema, es la "mortaja" de su creador. Aunque el poema sobreviva a su creador, también él perecerá. Asimismo, el poema es siempre un indicador de la mortalidad del que le da vida: 
Del habitante nada quedó en la playa sombría.

La concha que fue su obra

vivirá un poco más

y al fin tambicin se hará polvo (13).

¿Se engaña el poeta al creer haber logrado etemizarse por medio de su obra? No. No el poeta que como Pacheco rechaza el concepto romántico de "originalidad" y cree, en cambio, en el intertextualismo necesario de toda escritura. Pues, si bien la concha del caracol "se hará polvo", si el eco del mar que ella atesora volverá al mar, la poesía, que como todo lo creado envejece, encierra (oculta) un misterio que le permite estar continuamente evolucionando.

Agua que vuelve al agua, arena en la arena, sangre que se hunde en el torrente sanguíneo, circulación de las palabras en el mar del idioma:

la materia que te hizo único, pero tambiên afín a nosotros, jamás volverá a unirse, nunca habrá nadie igual que tú, semejante a ti, siempre desconocido en tu soledad pues, como todos, eres lo que ocultas (14).

Cada poema es único. Es la concha que se quiere "autopsiar en ausencia" (12); es el objeto de "un millón de preguntas sin respuesta" (12). Pero la vitalidad de ese poema único y de ese creador único reside en la intertextualidad, en la recirculación de las palabras, que son la materia del poema. Esto es lo que hace $\mathrm{Pa}$ checo, por ejemplo, en su poema "César Vallejo", en el cual no solo recrea el muy conocido poema del peruano "Piedra negra sobre una piedra blanca", sino que además responde al Vallejo que exclama en Poemas humanos: "Y si después de tantas palabras, / no sobrevive la palabra". La composición de Pacheco, escrita en el quincuagésimo aniversario de la muerte de Vallejo, finaliza con el siguiente verso: "Y uno habla y habla" (19). 
La poesía no sólo vive y (re)vive por medio de la reescritura, sino, y esencialmente, por medio de la lectura. Como observa Saúl Yurkievich, en poesía la lectura es siempre múltiple. Volviendo al primer poema de Ciudad de la memoria, es el eco del mar, el que atesora la concha del caracol y que sólo existe si el oído humano lo percibe, el que hace posible la continuidad de su misterio, al invitar a ese oído receptor a descifrar su indescifrable sonido. La repercusión de las palabras leídas/escuchadas le da vida al poema. Pues si bien, como dice el apócrifo poeta Julián Hemández, en Los trabajos del mar, "De pronto el corrosivo mar quedó escrito / en la íntima oreja del caracol y siguio resonando" (12), su resonancia es sólo un mensaje potencial. Sin ser leído, el poema es sólo "...words, words, words [...], que sólo es aire para que el aire lo escuche" ("Hamletiana" 17).

En "Para ti" el poema es un "papel roto" que el viento "sopla" para la calle en busca de un receptor. El hablante, que se dirige a un "tú"/lector, ignora las posibilidades de su lectura. Sólo está seguro de que el poema puede permanecer con una existencia palpitante en las "cavernas" del "aire", en la "nada", o ser actuado/leído y entonces multiplicar la comunicación. Así:

El viento sopla donde quiere:

lo lleva al ti o lo conduce a la nada

Es un milagro que tus ojos se posen en un papel de la calle.

Haz con él lo que quieras (39).

El poema queda abierto, porque, para decirlo con palabras de Yurkievich,

la poesía es la reveladora, la provocadora de la polifemia y polisemia latentes en toda escritura. La poesía es la conciencia y la memoria de la lengua, el instrumento más apto para explorar/ explotar todos los recursos de expresión, de selección, de composición, toda la capacidad de transformación, toda la creatividad posible de una lengua (72). 
El poema existe para ser leído o recreado.

No estamos sugiriendo, sin embargo, la existencia de una postura lúdica en la poética de Pacheco. Ya en Irás y no volverás el poeta indica que su propósito es ofrecer un testimonio "del momento que pasa":

\author{
A mí sólo me importa \\ el testimonio \\ del momento que pasa \\ las palabras \\ que dicta en su fluir \\ el tiempo en vuelo \\ La poesía que busco, \\ es como un diario \\ en donde no hay proyecto \\ ni medida (106).
}

Los poenas de Ciudad de la memoria tratan de dejar testimonio de todo lo que desaparece con el fluir del tiempo, ya que el tiempo mismo, la fugacidad, es lo único que permanece: "Para nosotros, los más efímeros de todos / una vez cada cosa. Nada más: nunca más. / Y nosotros también nunca de nuevo. / [..] Así vivimos siempre: despidiéndonos" (en "Bécquer y Rilke se encuentran en Sevilla" 44), de la violencia de nuestro siglo, de la violencia de la bestia humana ("El enemigo" 50). Se habla en esos poemas de la violencia de nuestro planeta: "Llegan las aves. Bajan en picada / y hacen vuelos rasantes y se elevan / con la presa en el pico: las tortugas / recién nacidas. Y no son gaviotas: / es la Luftwaffe sobre Varsovia [...]. / Que otros llamen a esto selección natural, / equilibrio de las especies. / Para mí es el horror del mundo" (en "Los mares del sur" 48-49). En un mundo donde predomina la muerte; la sangre, la destrucción - porque "Bajo el nombre/ del Bien / el mal se impuso" (27) -

"En "De paso" el hablante dice: "El tiempo no pasó: / aquí está. / Pasamos nosotros. Sólo nosotros somos el pasado" (Cilliad de la memoria 51). 
friente que, incapacitado para cambiar el curso de la historia, se autoasigna la función de cronista para un receptor desconocido. Así, el último poema del libro, basado en la traducción del inglés, por Bogdana y John Carpenter, de "Informe sobre la ciudad sitiada", del poeta polaco Zbigniew Herbert, resume esta postura. El poema de Pacheco no se aleja de la versión inglesa del de Herbert, porque la historia de Polonia, que a partir de 1772 es una historia de guerra y matanzas, de niños que no juegan sino con la muerte, sintetiza la historia de nuestro mundo y la postura del hablante poético se asemeja a la de Pacheco:

Demasiado viejo para empuñar las armas y pelcar como otros

bondadosamente me dieron el grado inferior de cronista

registro no sé para quiénes la historia del aseủio (60).

La poesía del horror obliga a una toma de conciencia. El hablante no invita a una comunión sentimental. La emoción se sustituye por la razón. El poeta/cronista dice: "todo es monótono sé que no puede conmover / a nadie / evito comentarios mantengo un control firme / sobre mis emociones / escribo acerca de los hechos" ( 61 ).

Pero la poesía testimonial es, como toda obra literaria, artificio, ficción, creación de la memoria. En "Informe sobre la ciudad sitiada", el hablante de Herbert a través del de Pacheco concluye diciendo: "y si cayera la Ciudad y un solo hombre escapara / lievará a la ciudad dentro de él por los caminos / del exilio / él será la Ciudad" (64). El rescate puntual de los hechos es tan imposible como la aprehensión del presente. Sin embargo, en el proceso de la creación artística, a través del cual la realidad objetiva se transforma en un producto que puede refiejar ciertas características del original, pero que nunca llega a ser su igual, este aparente fracaso de la poesía se vuelve su virtud. En el "El jardín en la isla" las rosas prolongan su existencia en la memoria del hablante: 
Mañana

ya no habrá rosas

pero la mirada

conservará su incendio (33).

El poeta/cronista, que desea que su obra se lea como "un diario", solo a un decenio del fin de siglo, tiene que registrar el debe y el haber de su tiempo. En "Los vigesémicos" el hablante, que se presenta en la primera persona del plural, en la sección inicial del poema acerca al lector hacia su perspectiva y le hace considerar este siglo como un "matadero sin fin que está muriendo / bajo el peso de todas sus victorias" (26). En el "nosotros" se unen el hablante y el receptor. Debemos creer que "seremos condenados" por la historia como "el estúpido siglo veinte" (25); porque nosotros, "los vigesémicos", según Francisco Montes de Oca y $\mathrm{Pa}$ checo, condenamos a nuestros antecesores, los decimonónicos. Pero en la segunda sección del poema la perspectiva del hablante cambia. El "nosotros" se dirige a un "ustedes". El lector se siente eximido de la nefasta herencia que el siglo veinte le deja al veintiuno: la explosión de basura que ha contaminado agua, aire y tierra, las matanzas, el sufrimiento. El ustedes/receptor señala a un lector implícito futuro, por cuya presencia el siglo se convierte en "un instante" y "su fin" en "un segundo" (27). La distancia que existe entre el hablante y el receptor, entre el "nosotros" y el "ustedes", sirve para que el lector medite sobre lo acontecido en este siglo con el que culmina el milenio.

Si el balance del siglo veinte parece ser negativo (hay muchos más horrores que virtudes), Ciudad de la memoria presenta una actitud positiva hacia la vida y hacia la creación artística. El reconocimiento del tiempo humano como finito y lineal causa sufrimiento, pero asimismo impulsa a apostar a la vida, a creer en los sueños, a crear. En "Live bait", poema que se divide en cinco partes, el hablante y el receptor, convertidos en "lombrices pensantes", con "lenguaje y conciencia" (59), por lo tanto, seres sufrientes al reflexionar que son "los encamados para ser camada", 
parecen coincidir -aunque el hablante en la última estrofa use la primera persona del singular-en que la vida "que se alimenta de la muerte" vale la pena de ser vivida.

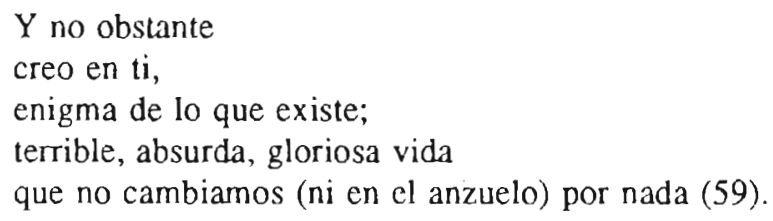

Si en la voz del hablante de "Live bait" creemos encontrar ecos del Vallejo que dice en Poemas humanos: "Me gustará vivir siempre, así fuese de barriga" (Vallejo 55), en la del hablante de "Certeza" se filtra la voz satisfecha del Neruda de Confieso que he vivido. El poema de Pacheco dice:

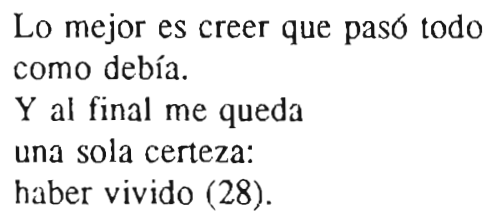

Pero el poema que mejor da cuenta de la actitud positiva de Pacheco hacia la vida y, por lo tanto, hacia la muerte es "Papel de trapos viejos". En él la actitud de Pacheco frente a la muerte se asemeja a la de Vallejo, ya que la concibe como creación. El hablante del poema se ve, o mejor dicho, ve su cuerpo, máscara con la que se enfrenta al tiempo, como un traje que se va desgastando, encogiendo, deshaciendo en el "ajetreo" de "la lavadora". Cuando el traje se convierte en un "trapo viejo" cobra nueva vida. Se transforma en "papel en blanco", donde necesariamente se ha de escribir una nueva historia.

Un trapo,

un trapo viejo el cuerpo.

Si algo de él sobrevive

será en cajón de sastre para servir de remiendo 
a otros vestuarios, o ser enviado al molino

en que de trapos viejos, cartones sucios

se hace el papel en blanco (24).

Recreación, reescritura, relectura, recuerdo, intertextualidad son las bases de la poética de Pacheco. Si coincidimos con Barthes en que el "yo" que se aproxima al texto acarrea consigo una "pluralidad de otros textos" (16-17), el hablante poético de Pacheco acerca las voces de otros poetas y revive las de aquellos que ya no están porque, como ya lo afirmaba en Irás y no volverás:

\section{Y cada vez que inicias un poema convocas a los muertos}

Ellos te miran escribir te ayudan (105).

\section{BIBLIOGRAFIA CITADA}

Barthes, Roland. S/Z. Paris: Seuil, 1970.

Bousoño, Carlos. "Poesía contemporánea y poesía postcontemporánea."

Teoría de la expresión poética. $4^{\mathrm{a}}$ ed., muy aumentada. Madrid: Gredos, 1966.

Browning, Robert. The Complete Poetic and Dramatic Works. Boston \& New York: Houghton Mifflin Company, 1985.

Colerdoge, Samuel Taylor. The Complete Poetical Works. Ed. Ernest Hartley Coleridge. 2 vols. Oxford: Clarendon Press, 1912.

- - "Biographia Literaria." The Norton Anthology of English Literature. Ed. M. H. Abrams et al. 2 vols. New York \& London: Norton, 1986. 2: $385-409$.

DEBICKI, AI DREW. "Perspectiva, distanciamiento y el tema del tiempo: la obra lírica de José Emilio Pacheco." José Emilio Pacheco ante la crítica. Ed. Hugo Verani. México: UAM, 1987. 47-56.

Doudoroff, Mrchael J. "José Emilio Pacheco: An Overview of the Poetry, 1963-86." Hispania 72 (1989): 264-276.

Frieurich, Hugo. The Structure of Modern Poetry. Trad. Joachim Neurogroschel. Evanston: Northwestem University Press, 1974.

Jarrell, Randall. Poetry and the Age. New York: Knopf, 1953. 
Lastra, Pedro. "Relectura de los raros." Texto Critico 5.12 (eneromayo 1979): 214-224.

Neruda, Pablo. Confieso que he vivido: Memorias. Mexico: Seix Barral, 1974.

Civiedo José Miguel. "José Emilio Pacheco: La poesía como "readymade»." Hispamérica 5:15 (1976): 39-55.

Pacheco, José Emmlo. Los elementos de la noche. México: UNAM, 1963.

- - El reposo del fuego. México: FCE, 1966.

- - No me preguntes cómo pasa el tiempo. México: Joaquín Mortiz, 1969.

- - Irás y no volverás. México: FCE, 1973.

_- Al margen. Paris: Colección Imaginaria, 1976.

- _. Jardín de niños. México: Ediciones Multiarte, 1978.

- - Desde entonces. México: Erà, 1980.

- Tarde o temprano. México: FCE, 1980.

- Prosa de la calavera. New York: Lenin Molina Tapia y el autor, 1981.

- Los trabajos del mar. Monterrey: Universidad Autónoma de Nuevo León, 1982; 2a ed. México: Era, 1983.

- - Miro la tierra. México: Era, 1986.

- - Ciudad de la memoria. México: Era, 1989.

Rodriguez-AlcalA, Hugo. "Sobre la poesía última de José Emilio Pacheco." Hispamérica 5.15 (1976): 57-69.

Soto, Lilvia. "Realidad de papel: máscaras y voces en la poesía de José Emilio Pacheco." José Emilio Pacheco ante la crítica. Ed. Hugo Verani. México: UAM, 1987.

Vallejo, César. Poemas humanos (1923-1938). 1939. $4^{\mathrm{a}}$ ed. Buenos Aires: Losada, 1961.

Wordsworth \& Coleridge. Lyrical Ballads. Ed. R. L. Brett and A. R. Jones. London and New York: Methuen, 1986. 